\title{
EXPERIMENTAL STUDY OF TURBULENCE AND VERTICAL TEMPERATURE PROFILE IN THE URBAN BOUNDARY LAYER
}

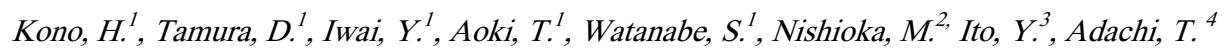 \\ ${ }^{1}$ University of Hyogo, ${ }^{2}$ Osaka Prefecture University, ${ }^{3}$ Kaijo Sonic Corporation, ${ }^{4}$ University of Yamanashi
}

\section{INTRODUCTION}

Recently dispersion of motor vehicle exhaust gas has been predicted using the new generation models in urban areas (Valkonen et al.,1995, Werferi, 1995). Monin-Obkhov similarity theory has been often used for these calculations. However, the similarity theory cannot be applied within the roughness sublayer where the flow is three-dimensional due to the influence of individual roughness elements. (Rotach, 1993). The reason why the similarity theory can not be applied in the roughness sublayer has not been known. Since the mechanical turbulence generated by buildings is large in the lower part of the urban boundary layer, it has possibilities to make deviations from the empirical formula in smooth sites (Monin-Obkhov similarity theory).

We studied the turbulence and vertical temperature profile in the lower part of urban boundary layer by conducting the field observations in Himeji City, wind tunnel experiments and numerical simulations.

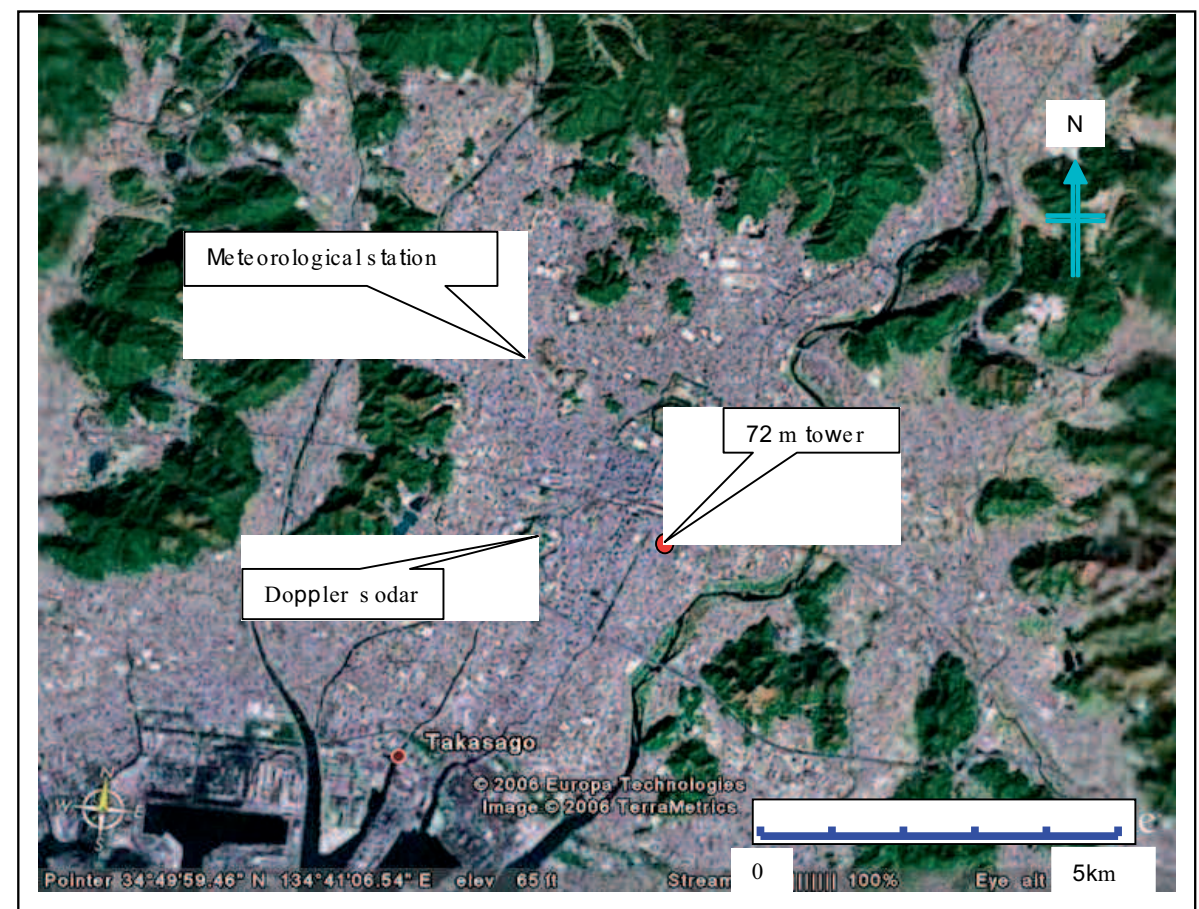

Figure 1. Urban area in Himeji city and site of a microwave-tower and the Doppler sodar.

Figure 1 shows the urban area in Himeji city and the site of the observation tower and the Doppler sodar. The urban area is flat and surrounded by hills of 150 to $200 \mathrm{~m}$ high in the south, west and east. Hills of $300 \mathrm{~m}$ high are in the north. The Seto inland sea is $5 \mathrm{~km}$ in the south. The downtown is in the north and the east of the tower with buildings of 10 to $45 \mathrm{~m}$ in height. In the south and the west of the tower, there is a commercial and residential area with houses and buildings of 7 to $30 \mathrm{~m}$ in height.

\section{OBSERVED VERTICAL TEMPERATURE AND TURBULENCE IN THE LOWER PART OF THE URBAN BOUNDARY LAYER}

The vertical profile of turbulence and temperature was studied experimentally in the urban area in Himeji City. For one year, the vertical profiles were observed at the $72 \mathrm{~m}$ tower and the urban surface temperature was observed on the top of a building. A tethered balloon was used to observe vertical temperature below $300 \mathrm{~m}$ in height for two days in July and November (Fig. 2). Turbulence was observed using sonic anemometers at the tower at $52 \mathrm{~m}$ and $71 \mathrm{~m}$ in height and using a Doppler sodar below $300 \mathrm{~m}$ in height. (Fig. 3). 


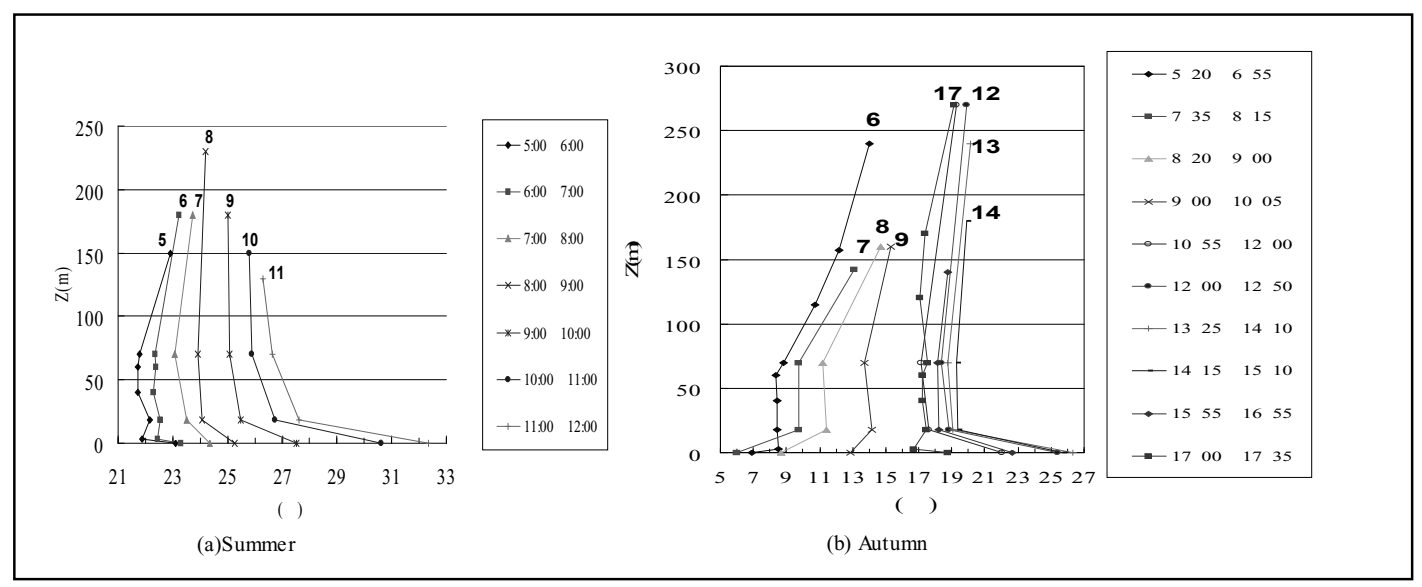

Figure 2. Vertical profile of potential temperature and surface temperature in summer (a: July 19th, 2007) and sutumn (b: November 8th, 2007) in an urban area of Himeji City, Japan.

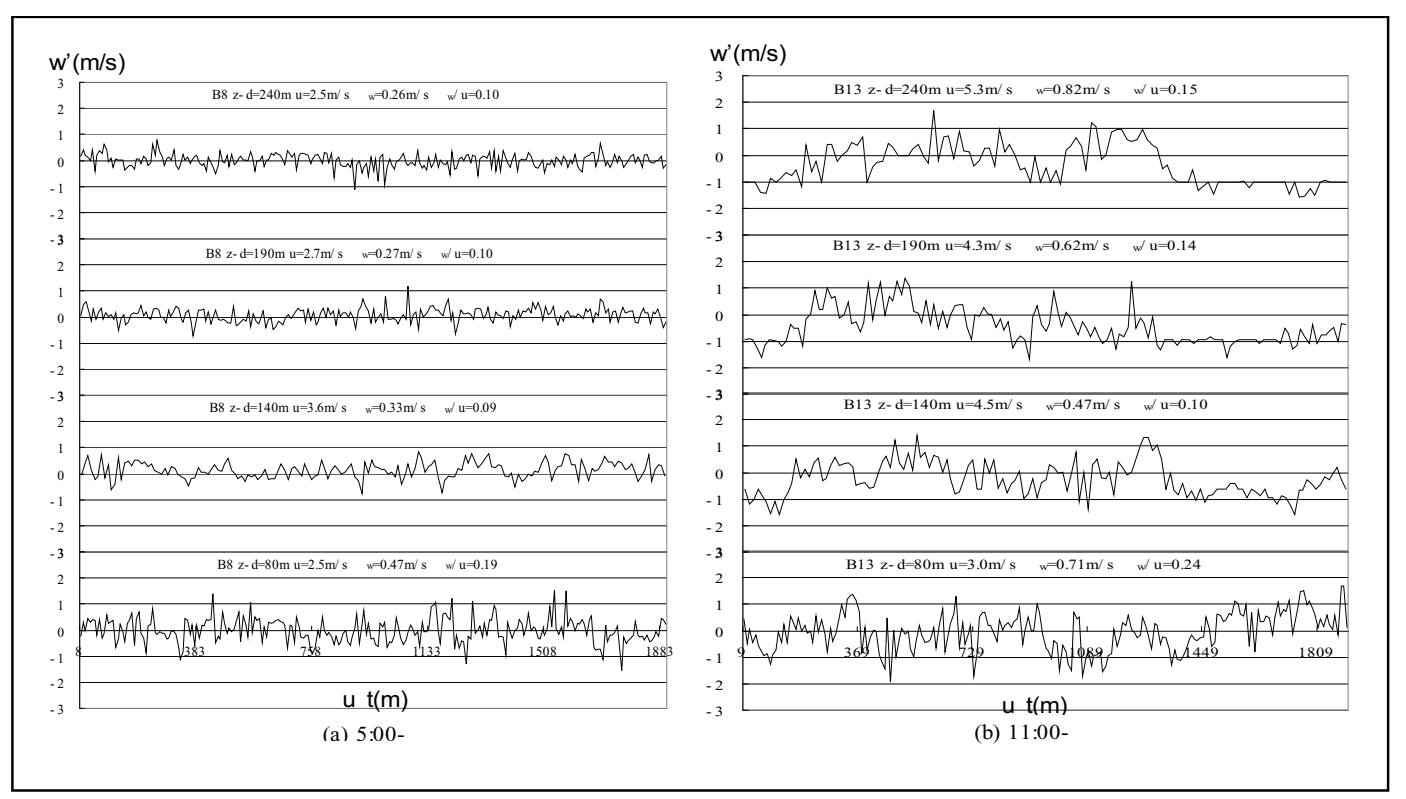

Figure 3. $W^{\prime}$ at (a) 5:00 - and (b) 11:00 - on July 19th (2007) measured using Doppler sodar in the center of Himeji city.

In clear night, the upper temperature inversion was observed through a year resulting in the radiation cooling. The height of the inversion base was $60 \mathrm{~m}$ above ground, which was 3 to 5 times the average building height. A neutral layer was observed under the inversion layer during night. The neutral layer must be the roughness sublayer (RS). In the upper inversion layer, turbulence intensity was smaller than those in RS.

\section{DEVIATION OF OBSERVED AND IN AN URBAN AREA FROM THOSE IN SMOOTH SITES}

In sunny day time, the RS was in unstable condition, since the observed potential temperature decreased with height $(-2 \% 100 \mathrm{~m}$; averaged value in August at 2 p.m.) and heat flux transported upward. However, the observed values of $u^{*} / u$ were close to that in neutral condition, where $u^{*}$ is the friction velocity and $u$ is the average wind speed, and they deviated large from the empirical formula presented by Businger et al., (1971) which fits observations at smooth sites. In addition, the observed values of $\sigma w / u^{*}$ were lower than the empirical formula presented by Panofsky et al., (1977) which fits observations at smooth sites in unstable condition.

These mean that the ratio of mechanical turbulence to convective turbulence is larger in urban areas than rural smooth areas. In addition, the convective turbulence transports momentum less effective in urban areas than rural area. This is also shown in the fact that in unstable condition, the correlation between $\mathrm{u}^{\prime}$ and $\mathrm{w}$ ' is weaker in urban areas $(\mathrm{R}=0$ to -0.2) (Fig. 5) than rural areas $(\mathrm{R}=-0.2$ to -0.35$)$ (Kaimal and Finnigan, 1994). Although the correlation between $W$, and $T^{\prime}$ in urban areas (Fig. 5) is the same as in rural smooth areas $\left(\mathrm{R}_{\mathrm{w}}{ }^{\prime}{ }^{\prime}=0.5\right)$ in unstable condition. In urban areas, 
convective turbulence transports heat $\left(\mathrm{R}_{\mathrm{w}} \mathrm{T}^{,}=0.5\right)$ but transports momentum less effectively in unstable condition. It means that the eddy diffusivity at the lower part of urban boundary layer, (z-d)/h=6 is different from that calculated from the empirical formula in smooth sites (Monin-Obkhov similarity theory) in unstable conditions, where $z$ is the height above the ground, $d(=2 \mathrm{~m})$ is the displacement height and $h(=9 \mathrm{~m})$ is the average building height.

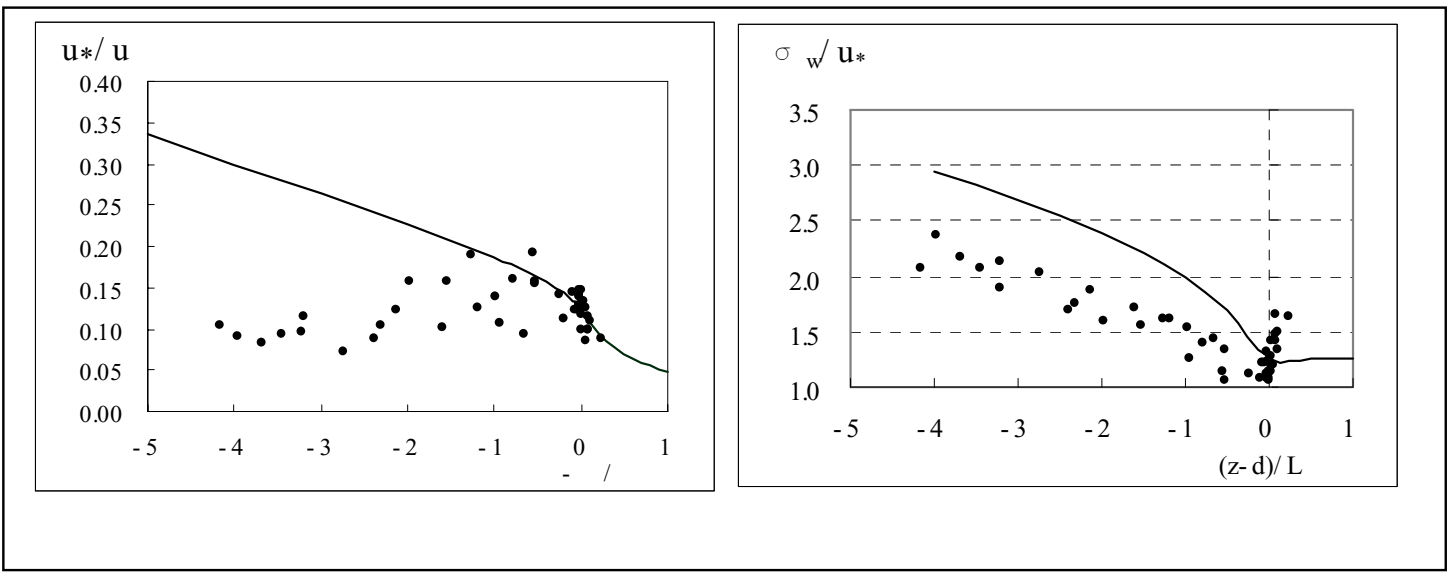

Figure 4. Observed $u^{*} / u, \sigma_{w} / u^{*}$ at the tower $(\mathrm{z}=54 \mathrm{~m})$ in Himeji city.

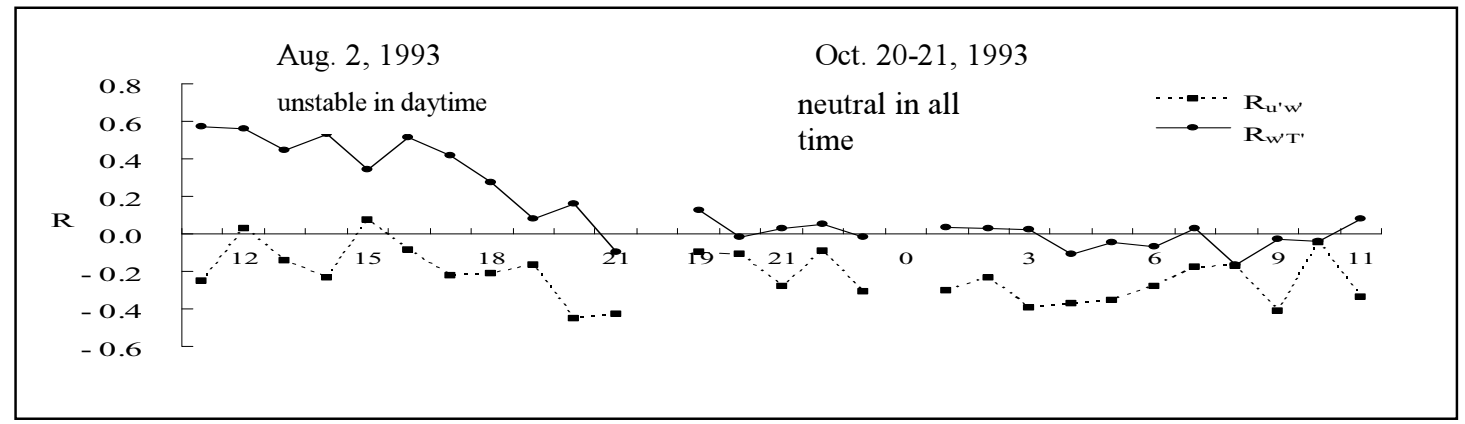

Figure 5. Observed $u^{\prime}$ and $w^{\prime}$ and correlation coefficients of $R\left(u^{\prime} w^{\prime}\right), R\left(w^{\prime} T^{\prime}\right)$ at tower (z=54m) in Himeji city. (Kono and Koyabu, $2005)$.

\section{WIND TUNNEL EXPERIMENTS}

The wind tunnel in our laboratory has a working section $3 \mathrm{~m}$ long, $0.3 \mathrm{~m}$ wide and $0.3 \mathrm{~m}$ high. In the wind tunnel, rough wall boundary layers were simulated using cubic roughness elements (of $18 \mathrm{~mm}$ cube) placed on the floor in diamond arrays. Turbulence was measured with a hot wire anemometer, and eddies were visualized by smoke.(Fig. 6) The spectrum of turbulence measured in the wind tunnel (Fig. 7), showed that, in RS, the size of eddies having maximum kinetic energy is scaled with the obstacle size. However, in the inertial sublayer (IS), it is scaled with the height above the displacement height. The eddy size which has maximum energy is proportional with height in IS.

\section{LES}

LES (Adaptive research-CFD 2000) was used to predict turbulent flow in the roughness sublayer. The dimensions of the computational domain were $150 \mathrm{~m} \times 22 \mathrm{~m} \times 12 \mathrm{~m}$ in the streamwise, span wise and normal directions respectively, with a grid spacing of $0.33 \mathrm{~m}$. It was resolved by $450 \times 66 \times 26$ cells. The $1.8 \mathrm{~m}$ cubes were placed on the base with similar diamond arrays to those in the wind tunnel (Fig. 6). The cube was 100 times as large as the roughness element in the wind tunnel. The inlet wind speed was $5 \mathrm{~m} \mathrm{~s}-1$ (uniform). The logarithmic wind profile wall function for a smooth surface was used to the lower boundary and the surface of cubes. The upper and both side boundary ( $\mathrm{x}-\mathrm{Z}$ cross section) conditions were free slip type. Figure 8 is the span wise and stream wise vorticities $\left(\omega_{x}, \omega_{y}\right)$. The calculated results (Fig. 8) shows that eddies are directly generated by cubes in the RS and they were transported downwind. 


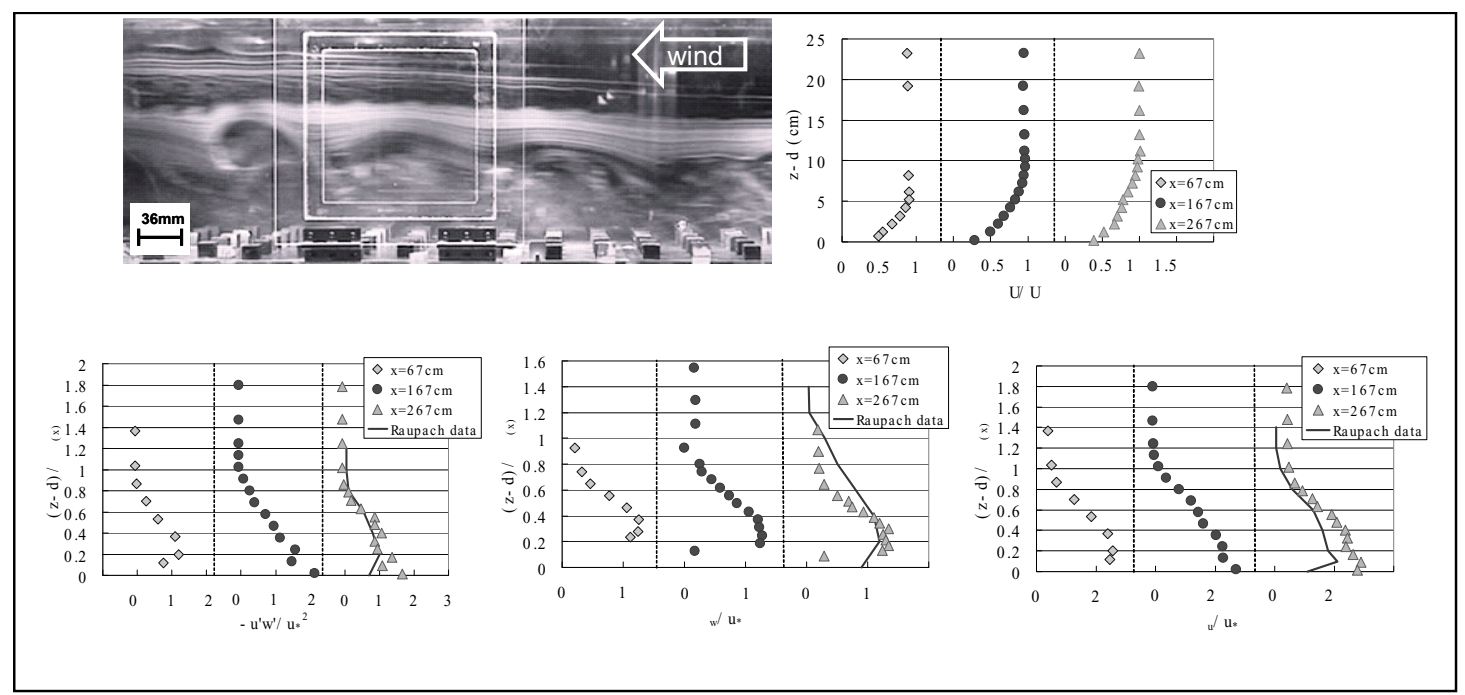

Figure 6. A visualization of the urban boundary layer and $U,-u^{\prime} W^{\prime} / u^{*^{2}}, \sigma_{w} / u^{*}, \sigma_{u} / u^{*}$ in the wind tunnel.

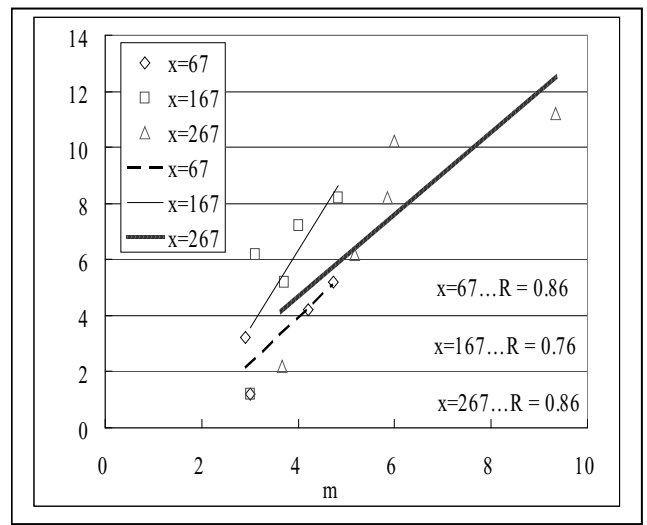

Figure 7. Eddy size which has maximum energy in the wind tunnel with height, $\mathrm{z}-\mathrm{d}$, and $\mathrm{x}$ in $\mathrm{cm}$.

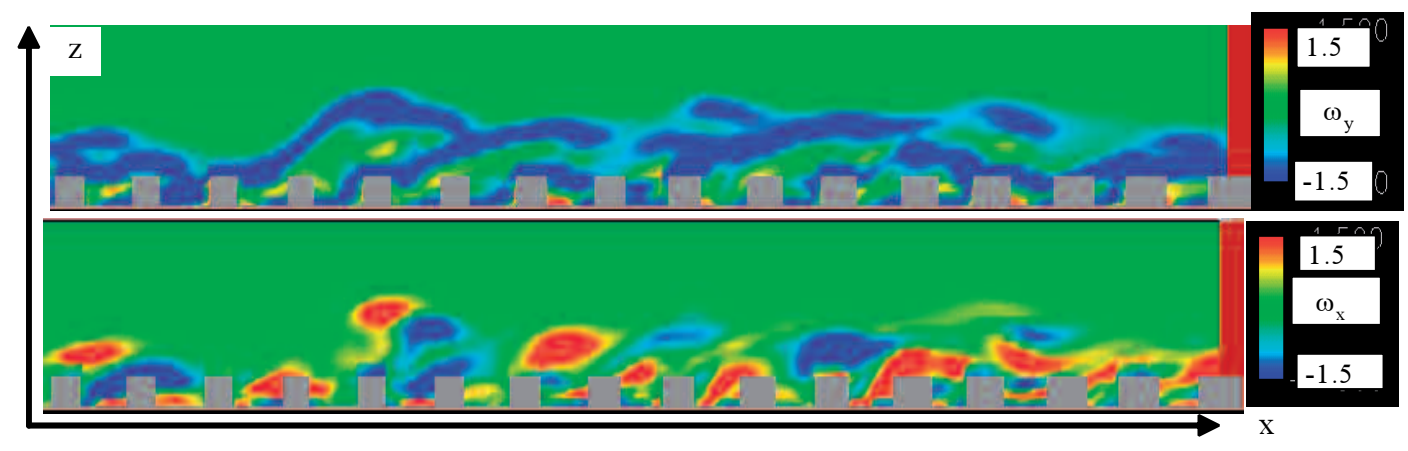

Figure 8 . Vorticity $\left(\omega_{\mathrm{x}}, \omega_{\mathrm{y}}\right)$

\section{CONCLUSION}

In the upper RS, in unstable condition, the observed values of $\mathrm{u}^{*} / \mathrm{u}$ were close to that in neutral condition, and they deviated large from the empirical formula presented by Businger et al.(1971) which fitted observations in smooth sites. In addition, the observed values of $\sigma_{\mathrm{w}} / \mathrm{u}^{*}$ were lower than the empirical formula presented by Panofsky et al.(1977) which fitted observations in smooth sites. The spectrum of turbulence measured in the wind tunnel, showed that, in IS, the eddy size which has maximum energy is proportional with height, on the other hand, in the RS, the 
size of eddies having maximum kinetic energy is scaled with the obstacle size. This is revealed by LES that in the RS, eddies were directly generated by cubes like wakes and they were transported downwind. The eddy structure in RS will be different from that in IS.

\section{REFERENCES}

Businger, J. A., J. C. Wyngaad, Y. Izumi and E. F. Bradley, 1971: Flux-profile relationships in the atmospheric surface layer. J. Atmospheric Science, 28, 181-189.

Kaimal, J.C. and J.J. Finnigan, 1994: Atmospheric Boundary Layer Flows, Capter1, 1-31.

Kono, H. and K. Koyabu, 2005: Proceedings of 10th international conference on hamonisation within atmospheric dispersion modeling for regulatory purposes, 445-449.

Panofsky, H. A., H. Tennekes, D. H. Lenschow and Wyngaard,J.C., 1977: The characteristics of turbulent velocity components in the surface layer under convective conditions. Boundary Layer Meteorology, 15, 439-446.

Raupach, M. R., 1981: Conditional statistics of Reynolds stress in rough-wall and smooth-wall turbulent boundary layers. J. Fluid Mech, 108, 363-382.

Rotach, M.W., 1993: Turbulence close to a rough surface Part 2: variances and gradients. Bound. Layer Met., 66, $75-$ 92.

Valkonen, E., J. Härkönen, J. Kukkonen, E. Rantakrans, L. Jalkanen and S. Haarala, 1995: Application of dispersion models for evaluating the influence of urban air pollution on human heath. Int. J. Environment and Pollution, 5, Nos. 4-6, 557-566.

Werfeli, M., 1995: Modelling surface pollutant concentrations in the city of Zürich. Int. J. Environment and Pollution, 5, Nos. 4-6, 575-584. 